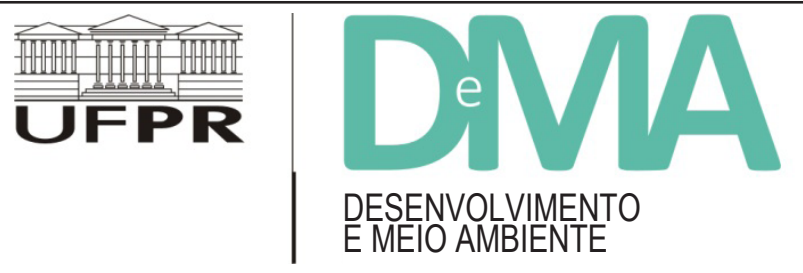

\title{
Uso de fichas ilustradas para seleção de espécies arbóreas nativas no planejamento participativo de sistemas agroflorestais com famílias agricultoras do Núcleo Luta Camponesa da Rede Ecovida de Agroecologia, PR
}

\section{Use of Illustrated Charts for Selection of Native Tree Species in the Participatory Planning of Agroforestry Systems with Farming Families from Núcleo Luta Camponesa of Rede Ecovida de Agroecologia, PR}

\author{
Gabriela Arruda CANOSA ${ }^{1 *}$, Julian Perez CASSARINO ${ }^{1}$, Josimeire LEANDRINI ${ }^{1}$ \\ ${ }^{1}$ Universidade Federal da Fronteira Sul (UFFS), Laranjeiras do Sul, PR, Brasil. \\ *E-mail de contato: gabycanosa@hotmail.com
}

Artigo recebido em 16 de março de 2016, versão final aceita em 23 de novembro de 2016.

RESUMO: A necessidade atual de estratégias relacionadas ao uso de espécies arbóreas nativas em unidades familiares de produção é consequência de diversos aspectos legais, históricos, ecológicos, sociais e econômicos. Dentre eles, destacam-se a obrigatoriedade legal de recomposição florestal nessas unidades, os benefícios socioeconômicos, a importância ecológica do componente florestal em agroecossistemas e a necessidade da revalorização do uso de espécies nativas em regiões tropicais. Diante disso, este trabalho objetiva descrever e analisar a seleção de espécies arbóreas nativas a partir do subsídio dado pelo uso de fichas ilustradas em planejamentos participativos de sistemas agroflorestais (SAFs), os quais foram realizados com grupos de famílias agricultoras de produção agroecológica. Para elaboração das fichas, realizou-se um levantamento bibliográfico que foi sistematizado em uma base de dados, acarretando a seleção de 72 espécies, incluídas em 33 famílias botânicas, consideradas com potencial atual para uso em SAFs e ocorrentes no território da Cantuquiriguaçu (PR) e entorno. Nas fichas constam informações sobre uso potencial, características ecológicas, grupo sucessional e outros atributos, expostos de forma didática para os agricultores. Sobre o contexto de utilização das fichas, estas foram apresentadas durante os planejamentos de $13 \mathrm{SAFs}$ realizados junto a quatro grupos ecológicos do Núcleo Luta Camponesa da Rede Ecovida de Agroecologia, o qual está inserido na Cantuquiriguaçu (PR). Dentre o total de 77 espécies escolhidas durante o planejamento para compor os SAFs, 57 são espécies arbóreas nativas e, destas, 54 estão incluídas nas fichas elaboradas. Dos objetivos inicialmente previstos, constatou-se que as fichas cumpriram com a finalidade de estimular o uso das espécies nativas nos SAFs planejados, funcionando como uma memória histórica dos(as) agricultores(as). No entanto, seu uso teve limitações por conta do volume de fichas e de informações, sendo sugerida a articulação com ferramentas metodológicas que facilitem a compreensão ou a pré-seleção das fichas antes das reuniões.

Palavras-chave: SAFs; agroecologia; espécies arbóreas nativas; agricultura familiar; metodologia participativa. 
ABSTRACT: The current need of strategies related to the use of tree species in family units of production is a result of various legal, historical, ecological, social and economical aspects. Among them we have the legal obligation of forest recovery in these units, the socio-economic benefits and ecological importance of the forest component in agroecosystems, and the need for upgrading the use of native species in tropical regions. Given this, the present work aims at describing and analyzing the selection of native tree species from the grant given by the use of illustrated charts in participatory planning of agroforestry systems, which were carried out with groups of farming families with agroecological production. For the preparation of charts, a bibliographical survey was made, which was systematized in a database built on this work, leading to the selection of 72 species, included in 33 botanical families, considered with potential for use in agroforestry systems and occurring in the territory of Cantuquiriguaçu/PR and surroundings. In the charts, the information about potential use, ecological characteristics, succession group, among other attributes, are included, exhibited didactically to farmers. In the context of use of chips, these were presented during the 13 planning agroforestry systems made with four ecological groups of Núcleo Luta Camponesa of Rede Ecovida de Agroecologia, which is inserted into the Cantuquiriguaçu/PR. Among the total of 77 species listed during the planning to compose the agroforestry systems, 57 are native tree species and, of these, 54 are included in the illustrated charts. From the objectives initially expected, it was found that the charts served with the purpose of encouraging the use of native species in the agroforestry systems planned, working as a historical memory of farmers. However, its use had limitations due to the volume of records and information, so it was suggested the joint with methodological tools to facilitate understanding or the pre-selection of the chips before the meetings.

Keywords: agroforestry systems; Agroecology; native tree species; family agriculture; participatory methodology.

\section{Introdução}

Diante do contexto histórico de devastação das florestas brasileiras (SOS Mata Atlântica \& INPE, 2014) e da necessidade atual de adequação ambiental dada pela Lei $\mathrm{n}^{\circ} 12.651$, de 25 de maio de 2012 (Brasil, 2012), vem se tornando cada vez mais nítida a relevância da recomposição florestal nas propriedades rurais, o que inclui a importância de um trabalho junto às unidades familiares. Unindo essa necessidade à influência do componente arbóreo na dinâmica de agroecossistemas sustentáveis (Gliessman, 2002) e à importância socioeconômica dada pelos potenciais de uso dos produtos florestais madeireiros e não madeireiros (Santos et al., 2003), as espécies florestais podem cumprir papel relevante nas estratégias de reprodução social dos atores rurais.

É nesse sentido que a inserção do componente arbóreo merece destaque na construção de unidades produtivas de base agroecológica, visando a estra- tégias para o desenvolvimento rural sustentável. Além disso, essa inserção deve vir acompanhada da preocupação com a revalorização e o estímulo ao cultivo e ao manejo de espécies florestais nativas, considerando o papel dessas espécies tanto nas dinâmicas ecológicas quanto em relação aos seus potenciais de uso e retorno financeiro, que podem contribuir para a reprodução social e econômica de agricultoras e agricultores familiares.

Um dos pressupostos para a construção do conhecimento na agroecologia é a participação dos atores rurais como agentes da sua própria mudança e nos processos de aprendizagem (Sevilla-Guzman, 2006). Assim, o uso de metodologias participativas na construção de sistemas agroflorestais propicia o diálogo entre pesquisador(a) e agricultor(a) e possibilita o resgate de saberes tradicionais sobre a dinâmica e o manejo dos agroecossistemas, facilitando a tomada de decisões e o consequente desenho de sistemas de produção de base ecológica (ANA, 2007; Campolin \& Feiden, 2011). 
Assim, este trabalho objetiva descrever e analisar a seleção de espécies arbóreas nativas regionais a partir do subsídio dado pelo uso de fichas ilustradas no planejamento participativo de sistemas agroflorestais (SAFs) em unidades familiares de produção agroecológica. Eses planejamentos foram realizados com quatro grupos de agricultores familiares do Núcleo Luta Camponesa da Rede Ecovida de Agroecologia (localizado no território da Cantuquiriguaçu e entorno, PR) e levaram em consideração aspectos ambientais, sociais e econômicos das unidades familiares de produção, bem como os objetivos das famílias com os SAFs.

\subsection{A fitofisionomia da Cantuquiriguaçu e as espécies florestais de ocorrência na região}

A contextualização sobre a fitofisionomia do território da Cantuquiriguaçu assume particular relevância pelo fato de este se caracterizar como uma região de ecótono entre a Floresta Ombrófila Mista (FOM) e Floresta Estacional Semidecidual (FES) (IBGE, 2012), o que tem influência marcante na ocorrência das espécies nativas e, consequentemente, na escolha das espécies a serem implantadas nos SAFs de acordo com a localidade em que os grupos estão inseridos.

O território encontra-se quase que integralmente inserido na FOM, em sua maioria na subformação Montana, porém, com presença das subformações Altomontana e Submontana, bem como dos Campos Naturais (associados à FOM). No entanto, conforme já observado, os estudos mais recentes sobre a fitofisionomia do estado do Paraná mostram que boa parte da área de ocorrência atribuída à FOM caracteriza-se como região de transição entre essa formação e a FES (nas subformações Montana e Submontana), sendo que grande parte do território da Cantuquiriguaçu encontra-se nessa condição natural, como pode ser observado na Figura 1.

Mais especificamente, os quatro municípios presentes neste estudo estão incluídos total ou parcialmente nessa área de ecótono, bem próximos da linha considerada por Castella \& Britez (2004) como limítrofe entre o ecótono e a área de FOM propriamente dita, mas também da linha limítrofe entre o ecótono e a área de FES, considerando a área de influência do rio Iguaçu (Figura 1). A porção norte do território está sob influência do rio Piquiri, região que possui fitofisionomia mais característica de FES. Segundo Castella \& Britez (2004), a floresta estacional semidecidual adentra a FOM a partir dos vales de grandes rios como Iguaçu, Tibagi, Ivaí e Piquiri.

Segundo Pires (2003), a região do ecótono entre FOM e FES, no estado do Paraná, apresenta baixa densidade de pinheiros e possui representatividade das características de FES. Castella \& Britez (2004) defendem que há uma gradação na estrutura e na composição florística à medida que se distancia da FOM em direção à FES. Na porção mais próxima da FES, a presença da araucária é esporádica.

O estudo de Viani et al. (2011) compilou dados de 52 levantamentos fitossociológicos realizados em áreas de FES e FOM e os autores concluíram que algumas espécies são típicas às duas fitofisionomias, levando a crer que são as mais adaptadas em áreas de transição. Entretanto, adicionam que espécies típicas exclusivamente de uma ou outra fitofisionomia também podem ocorrer nessas áreas. Segundo os autores, são espécies típicas às duas fitofisionomias: guabirobeira (Campomanesia xanthocarpa (Mart.) O.Berg), pessegueiro-bravo (Prunus myrtifolia (L.) Urb.), guaçatunga (Casearia decandra Jacq.), cedro (Cedrela fissilis Vell.), cafezeiro-do-mato (Casearia sylvestris Sw.), miguel-pintado (Matayba elaeagnoides Radlk.), 


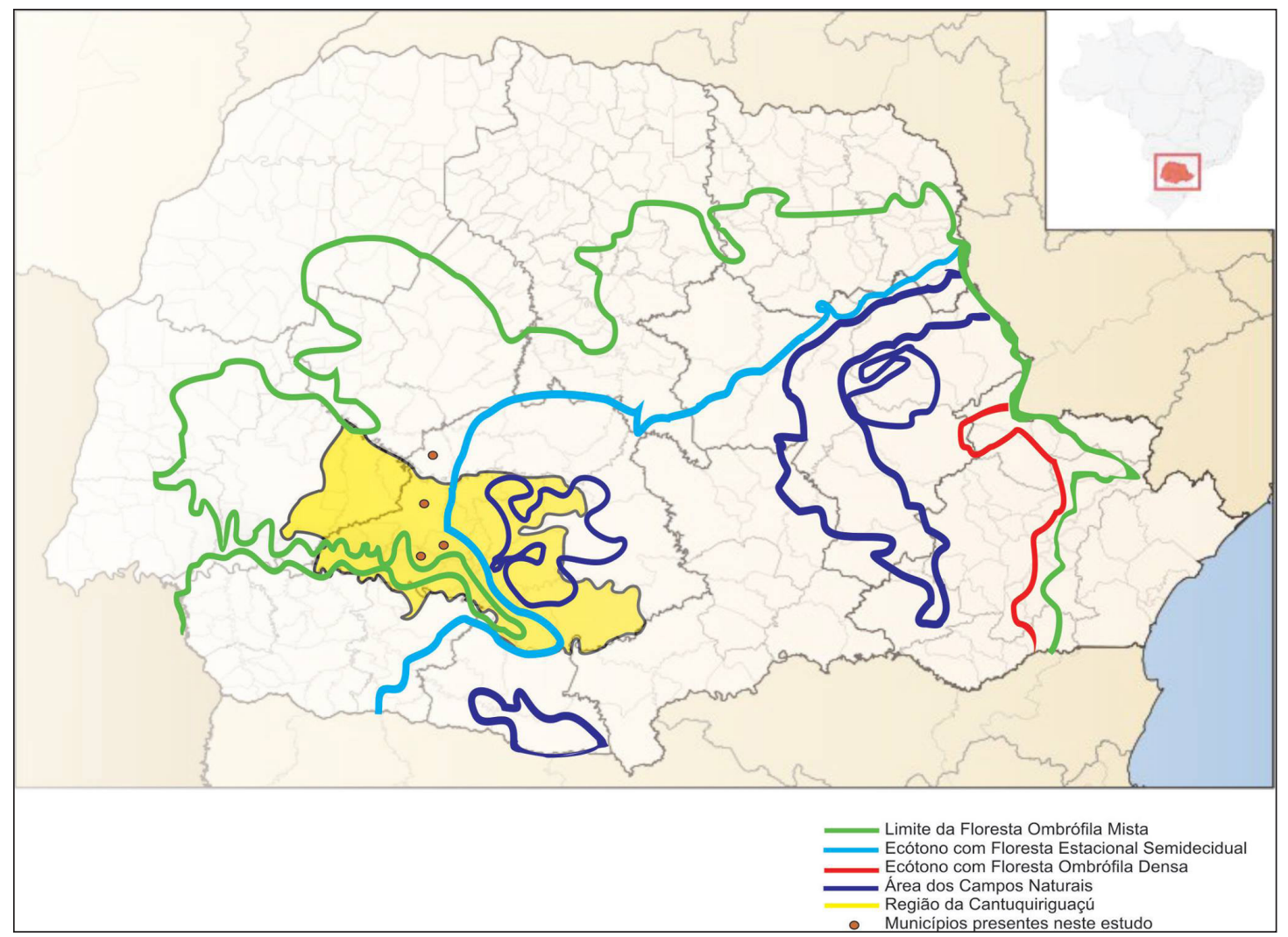

FIGURA 1 - Mapa com os limites fitogeográficos no estado do Paraná, incluindo as regiões de ecótono entre Floresta Ombrófila Mista (FOM) com Floresta Estacional Semidecidual (FES) e Floresta Ombrófila Mista com Floresta Ombrófila Densa (FOD). O destaque em amarelo é a indicação aproximada da localização da região da Cantuquiriguaçu no Paraná, parte no ecótono entre FOM e FES.

FONTE: modificada de Castella \& Britez (2004).

canela-preta (Nectandra megapotamica (Spreng.) Mez), jerivá (Syagrus romanzoffiana (Cham.) Glassman), vacum (Allophylus edulis (A. St.-Hil., Cambess. \& A. Juss.) Radlk.), miguel-pintado (Cupania vernalis Cambess.), capororocão (Myrsine umbellata Mart.), sapuva (Machaerium stipitatum (DC.) Vogel), canela-guaicá (Ocotea puberula (Rich.) Nees), canjerana (Cabralea canjerana (Vell.) Mart.), açoita-cavalo (Luehea divaricata Mart.), guamirim-miúdo (Myrcia splendens (Sw.) DC.), carvalho-brasileiro (Roupala brasiliensis
Klotzsch), branquilho (Sebastiania commersoniana (Baill.) L.B. \& Downs), leiteiro (Sebastiania brasiliensis Spreng.), mamica-de-porca (Zanthoxylum rhoifolium Lam.), pau-de-leite (Sapium glandulosum (L.) Morong), pitanga (Eugenia uniflora L.), guaçatunga-vermelha (Casearia obliqua Spreng.), cerejeira-do-rio-grande (Eugenia involucrata DC.), tamanqueira (Aegiphila sellowiana Cham.), chal-chal (Allophylus guaraniticus (St. Hil.) Radlk).

Em Castella \& Britez (2004) há resultados de um trabalho de campo feito em toda a extensão 
da Floresta com Araucária no estado do Paraná, incluindo a região de transição entre esta e a FES. Com isso, observaram que a distribuição de algumas espécies acompanha a ocorrência do ecótono, a exemplo de: grápia (Apuleia leiocarpa (Vogel) J. F. Macbr.), peroba-rosa (Aspidosperma polyneurum (Mull-Arg)), pau-marfim (Balfourodendron riedelianum (Engl.) Engl.), louro-branco (Bastardiopsis densiflora (Hook.\&Ajn.) Hass1.), araribá (Centrolobium tomentosum (Guillemin exBenth)), paineira (Ceiba speciosa (A. St.-Hil.) Gibbs \& Semir), louro-pardo (Cordia trichotoma (Vell.) Arráb. ex Steud.), pau-de-alho (Gallesia gorazema (Vell) noq.), canafístula (Peltophorum dubium (Spreng.) Taub.), cebolão (Phytolacca dioica L.), jaborandi (Pilocarpus pennatifolius (Lem.)). É importante destacar que nenhuma das espécies citadas por Castella \& Britez (2004) é comum às citadas por Viani et al. (2011) como típicas às duas fitofisionomias, sendo esses trabalhos contraditórios ou complementares quanto a essas informações.

A Floresta Estacional Semidecidual é caracterizada pela semideciduidade da folhagem da cobertura florestal, consequência da ocorrência de clima estacional duplo, com um período frio e seco no inverno, quando $20 \%$ a $50 \%$ das árvores que constituem o dossel perdem suas folhas (IBGE, 2012). No Paraná, predomina nas regiões norte, noroeste e oeste (ITCG, 2009). A espécie arbórea mais característica, que domina o dossel entre $30 \mathrm{~m}$ e $40 \mathrm{~m}$ de altura, é a peroba-rosa (Aspidosperma polyneuron) (Roderjan et al., 2001). Segundo Corandin et al. (2011), também é constituída predominantemente das espécies: ipê-roxo (Handroanthus heptaphyllus (Vell.) Mattos), pau-marfim (Balfourodendron riedelianum), canafístula (Peltophorum dubium) e louro-pardo (Cordia trichotoma). É interessante notar que algumas dessas espécies, típicas de FES, também foram citadas por Viani et al. (2011) e
Castella \& Britez (2004) como ocorrentes na região de ecótono, entre esta e a FOM.

A FOM ocorre principalmente nas áreas frias e altas do Planalto Meridional Brasileiro na região Sul (Corandin et al., 2011) e, no estado do Paraná, ocupa $41,5 \%$ da área total (Castella \& Britez, 2004). É caracterizada por apresentar três estratos arbóreos, sendo o estrato superior com mais de $30 \mathrm{~m}$ de altura dominado pelo pinheiro-do-paraná (Araucaria angustifolia (Bertol.) Kuntze), além de um estrato arbustivo e um herbáceo (Klima et al., 2013; Roderjan et al., 2001). Segundo Corandin et al. (2011), pode-se determinar duas comunidades distintas na FOM. A primeira, onde a A. angustifolia se distribui de forma esparsa e onde as espécies imbuia (Ocotea porosa), canela-amarela (Nectandra lanceolata Nees), canela-preta (N. megapotamica), guabirobeira (Campomanesia xanthocarpa) e erva-mate (Ilex paraguariensis A.St.-Hil.) são frequentes. E a outra, onde há grande densidade de indivíduos de $A$. angustifolia e onde há representatividade de espécies como canela-lageana (Ocotea pulchella (Nees \& Mart.) Mez), canela-amarela ( $N$. lanceolata), canela-guaicá ( $O$. puberula), pinheiro-bravo (Podocarpus lambertii Klotzsch ex Endl.), pimenteira (Capsicodendron dinisii (Schwacke) O.) e outras Myrtaceae e Lauraceae.

\subsection{A importância da escolha das espécies florestais nativas no planejamento de SAFS}

O potencial endógeno e a valorização do local têm destaque nas discussões sobre agroecologia (Caporal, 2009; Toledo \& Barrera-Bassols, 2015). É nesse sentido que a utilização das espécies nativas deve ser vista como proposta central, porém não limitada, em estratégias para a (re)introdução do componente arbóreo nos agroecossistemas. Para aumentar a possibilidade de que os objetivos dos 
SAFs sejam alcançados, é importante um bom planejamento. Para isso, deve-se dar atenção à escolha das espécies, a qual deve relacionar o histórico e ambiente local, os respectivos atributos e funções que as espécies cumprem no ecossistema (Engel \& Parrota, 2003; SER, 2004) e a importância cultural, social e econômica para os habitantes locais.

A capacidade de prover produtos florestais madeireiros (PFMs) e não madeireiros (PFNMs) é um atributo importante na seleção de espécies arbóreas. Agregar valor econômico e social a uma floresta significa incentivar famílias agricultoras a recomporem áreas de reserva legal (RLs) e áreas de preservação permanente (APPs) (Brasil, 2012), bem como incorporar as árvores em seus sistemas de produção, sem julgá-las como um empecilho à economia familiar. Esses produtos podem representar alternativas à geração de renda e à subsistência da família (Santos et al., 2003), diminuindo a dependência de produtos externos. As espécies de uso múltiplo, ou seja, aquelas capazes de fornecer mais de um produto e/ou função, merecem destaque pelo potencial de aumentar a produtividade do sistema (Silva, 2013).

A classificação exata de PFM e PFNM é incerta atualmente. Isso porque autores consideram diferentes recursos para cada categoria. Santos et al. (2003) fazem uma síntese dos diferentes conceitos e classificações existentes para PFNM. Carvalhaes et al. (2008) sugerem que os PFMs são utilizados para estrutura, energia, movelaria, artesanato, produção de pequenos objetos, instrumentos musicais, caixotaria, tornearia e construção naval, enquanto os PFNMs teriam uso paisagístico, artesanal, medicinal, apícola, cosmético ou farmacêutico, alimentício, como corantes, na produção de mudas e sementes, óleos, fibras e produtos químicos. Gomes et al. (2013) exploram o resgate do conhecimento de famílias agricultoras sobre as espécies arbóreas nativas e identificam grande diversidade de usos históricos dados pelos(as) agricultores(as).

Um aspecto que deve ser levado em consideração é a desvalorização histórica das espécies nativas diante de uma cultura globalizada e homogeneizada (Santilli, 2009; Toledo \& Barrera-Bassols, 2015). Com relação às espécies arbóreas, essa situação é agravada diante dessa cultura que supervaloriza espécies exóticas, a exemplo de Pinus sp. e Eucalyptus sp., usadas em plantios silviculturais desenvolvidos tecnologicamente, e coloca em segundo plano o uso de espécies nativas com diversos usos potenciais, inclusive madeireiro. Dessa forma, a desvalorização das árvores nativas é também uma questão cultural e histórica, possivelmente mais do que por aspectos econômicos.

Por outro lado, o uso das plantas exóticas não pode ser condenado. Muitas têm papel comercial importante nos SAFs. Como exemplo, aproximadamente $85 \%$ das espécies florestais de valor comercial (desconsiderando as variedades) produzidas por sete famílias da Cooperafloresta ${ }^{1}$ quantificadas entre 2009 e 2011 são exóticas (Fonini \& Lima, 2013). Para enfatizar, a Cooperafloresta é conhecida por implantar SAFs sucessionais estratificados e biodiversos e que valorizam espécies locais, o que reflete o fato de que $89 \%$ das espécies levantadas no conjunto de 16 agroflorestas são de ocorrência natural da Mata Atlântica (Steenbock et al., 2013). Isso mostra que, no caso da Cooperafloresta, mesmo que a maior parte de espécies que compõem a estrutura dos SAFs seja nativa, as exóticas não deixam de ter

\footnotetext{
1 A Cooperafloresta é uma organização que reúne famílias agricultoras dos municípios de Barra do Turvo (SP), Adrianópolis (PR) e Bocaiuva do Sul (PR), na região do Vale do Ribeira, fronteira entre os estados de São Paulo e Paraná (Cooperafloresta, 2016). Atualmente é formada por 110 famílias que produzem SAFs, sendo uma das maiores experiências de agroflorestas conhecidas no estado.
} 
grande importância na comercialização e na geração de renda monetária para as famílias envolvidas.

Dessa forma, a questão aqui colocada não diz respeito à exclusão de espécies exóticas dos agroecossistemas ecológicos, mas, sim, de que também se deve valorizar as nativas como espécies potenciais em oferecer serviços ecológicos e bens de utilização. Esse raciocínio foi um dos grandes motivadores do desenvolvimento desta pesquisa, e a elaboração das fichas ilustradas de espécies nativas de ocorrência regional foi uma forma de incentivo à revalorização dessas espécies.

\section{Metodologia}

\subsection{A elaboração das fichas}

Para a elaboração das fichas ilustradas de espécies arbóreas da região da Cantuquiriguaçu (PR) foram realizadas quatro etapas: i) levantamento bibliográfico sobre espécies nativas regionais, suas características ecológicas e seus usos potenciais; ii) sistematização das informações coletadas na bibliografia em uma base de dados construída em planilha eletrônica a partir desse trabalho; iii) seleção das espécies prioritárias da região com importância para SAFs; e iv) montagem gráfica das fichas, que contou com a colaboração de um designer gráfico para diagramação e arte.

A busca das espécies ocorrentes na região foi feita inicialmente em levantamentos fitossociológicos, mas apenas as consideradas como potenciais para uso em SAFs compuseram as fichas. Para a seleção das espécies prioritárias, foram utilizados os critérios: i) espécies arbóreas nativas da região da Cantuquiriguaçu (PR); ii) espécies com potencial de uso (Corandin et al., 2011; Carvalho, 2003; 2006; 2008; 2010; Lorenzi, 2002a; 2002b; 2009; Saueressig, 2015); e iii) disponibilidade de mudas nos viveiros da região ${ }^{2}$ (IAP, 2015; Comunicação pessoal, Anderson Gibathe - ENGIE). Também foram resgatadas informações sobre as espécies selecionadas presentes na base de dados construída anteriormente pela autora ${ }^{3}$ (Canosa, 2013). A confirmação de ocorrência em pelo menos um dos municípios da região foi realizada a partir de dados de herbários virtuais (INCT, 2015). A lista de referências utilizadas está na Tabela 1.

TABELA 1 - Bibliografia utilizada para o levantamento das espécies arbóreas da região da Cantuquiriguaçu (PR) com potencial para uso em sistemas agroflorestais.

\begin{tabular}{cc}
\hline Código da referência & Referência bibliográfica \\
\hline 1 & Isernhagen, 2001 \\
2 & Viani et al., 2011 \\
3 & Inct, 2015 \\
4 & Corandin et al., 2011 \\
5 & Carvalho, 2003 \\
6 & Carvalho, 2006 \\
7 & Carvalho, 2008 \\
8 & Carvalho, 2010 \\
9 & Carvalho, 2014 \\
10 & Lorenzi, 2002a \\
11 & Lorenzi, 2002b \\
12 & Lorenzi, 2009 \\
13 & Inoue et al., 1984 \\
14 & Saueressig, 2015 \\
15 & Lorenzi, 2004 \\
16 & Canosa, 2013 \\
\hline
\end{tabular}

FONTE: Elaboração dos autores.

\footnotetext{
2 Por se tratar de um trabalho de campo, onde as fichas subsidiaram o planejamento de SAFs junto a famílias agricultoras, considerou-se que a disponibilidade de mudas deveria ser um critério determinante para a seleção de espécies, principalmente pela questão da viabilidade de implantação.

3 A base de dados construída anteriormente pela autora, apresentada em parte em Canosa (2013), inclui espécies potenciais para uso em recuperação de áreas degradadas da Mata Atlântica, selecionadas a partir dos atributos: usos potenciais, fixação biológica de nitrogênio e atratividade à fauna.
} 
Sobre as informações das espécies, estas incluem potencial de uso, características ecológicas (exigência luminosa, clima), formas de propagação, ocorrência nas fitofisionomias na região (FES, FOM e transição entre as duas), crescimento, fenologia e grupo sucessional.

Sobre os potenciais de uso, foram sistematizadas informações sobre: (i) finalidade do uso, classificada em apícola, alimentação, artesanato, combustível (lenha, carvão), ecológico (reflorestamento), fibras, forragem, madeira, medicinal, ornamental e produto bioquímico (tanino, saponina, resina); (ii) características do uso, quando encontrado (ex.: madeira para movelaria); e (iii) parte do vegetal utilizada para cada uso (Santos et al., 2003). As espécies foram organizadas por família e para cada espécie foi registrada a referência das respectivas bibliografias por meio de números que as indicam em outra listagem.

Além das informações sobre características ecológicas e potenciais de uso, as fichas também estavam compostas de fotos das espécies retiradas de Lorenzi (2002a; 2002b; 2009) e Saueressig (2015). Para cada espécie, foram selecionadas quatro fotos, que incluem porte da árvore e características da folha, do fruto e da madeira. Com o objetivo de facilitar a compreensão dos agricultores, as informações foram apresentadas em forma de ícones ilustrativos, elaborados para este trabalho com a colaboração do designer gráfico. Para cada ícone referente aos usos potenciais e às características ecológicas há uma legenda que o descreve (Figura 2).

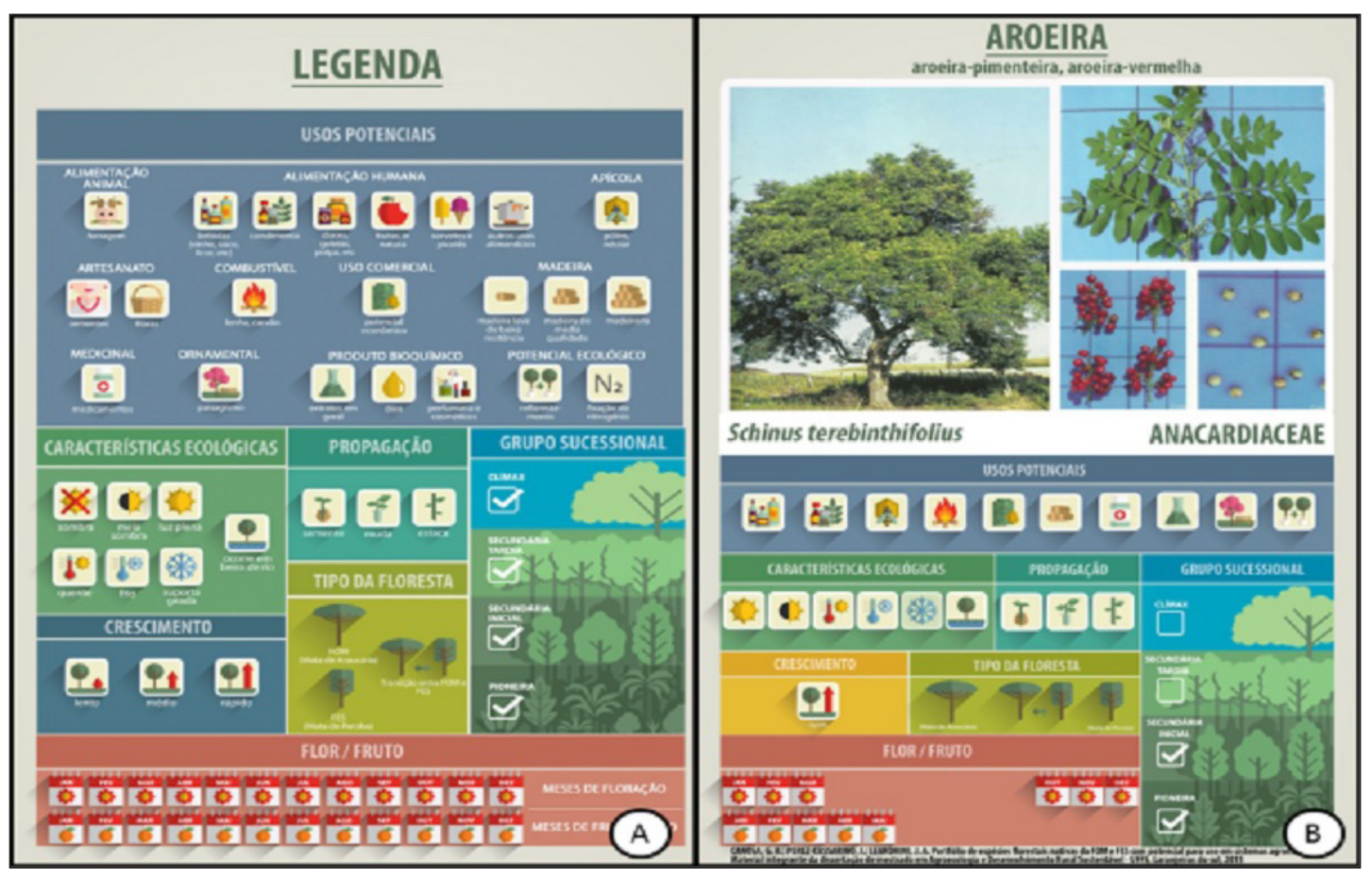

FIGURA 2 - Exemplo das fichas ilustradas de espécies florestais nativas da região da Cantuquiriguaçu - PR com potencial para uso em sistemas agroflorestais (SAFs), utilizadas para auxiliar na escolha das espécies no planejamento participativo de SAFs na Cantuquiriguaçu. FONTE: Elaboração dos autores. 


\subsection{O contexto de utilização das fichas}

As fichas ilustradas foram utilizadas para auxiliar na escolha das espécies a serem implantadas nos SAFs planejados de forma participativa em quatro grupos ecológicos do Núcleo Luta Camponesa da Rede Ecovida de Agroecologia, o qual está inserido no território da Cantuquiriguaçu (PR) e abarca alguns municípios do entorno. Os grupos estão indicados por números de acordo com a ordem de reuniões realizadas (ex.: grupo 1, grupo 2...). Esse trabalho faz parte da dissertação de mestrado da autora e teve a metodologia realizada em três etapas: i) pré-diagnóstico e escolha dos grupos de trabalho; ii) diagnóstico e planejamento dos sistemas agroflorestais; e iii) avaliação do processo participativo, realizada a partir de um questionário impessoal. Outros níveis de avaliação se deram a partir da avaliação da equipe de trabalho, o que permitiu que a metodologia proposta fosse mutável e flexível.

A primeira etapa, (i), ocorreu em conjunto com as atividades realizadas pelo Núcleo Luta Camponesa da Rede Ecovida e foi realizada em quatro passos: i) entrevistas preliminares semiestruturadas; ii) divulgação a partir de fôlderes informativos; iii) seleção de quatro grupos de trabalho (GTs) com três a cinco famílias cada; e iv) cadastro dos GTs definidos. As famílias participantes foram identificadas a partir do número do grupo (1 a 4) e da ordem do planejamento do SAF por meio das letras A, B, C ou D. Como exemplo, a família 1D foi a quarta família do grupo 1 a planejar o SAF, e a família $3 \mathrm{~A}$ foi a primeira família do grupo 3 a fazê-lo.
A segunda etapa contemplou reuniões de diagnóstico e de planejamento. $\mathrm{O}$ uso das fichas se deu nas reuniões de planejamento, tendo sido planejados um ou dois SAFs por reunião, totalizando de duas a três reuniões por grupo. No início das reuniões foram apresentadas as fichas e a legenda com os ícones, além de sugerida uma forma de utilização. A separação das fichas seguiu algumas etapas: i) de acordo com o tipo de floresta predominante no local ${ }^{4}$; ii) de acordo com os objetivos da família, incluindo as espécies que possuem os potenciais de uso de interesse; e iii) consideração das características das espécies de acordo com a área de implantação. Adicionalmente, para os objetivos de produção de alimento e/ou apícola, houve a etapa iv) consideração da fenologia das espécies de forma que haja frutos e/ou floração disponível na maior parte do ano.

Parte-se do pressuposto de que a metodologia utilizada para o planejamento dos SAFs deve fazer uso das fichas de forma que estas dialoguem com o conhecimento acumulado pelos(as) agricultores(as) sobre as características de cada espécie. Por isso, o uso das fichas foi proposto de forma arbitrária: no momento do desenho dos SAFs, as fichas foram deixadas à mostra para uso facultativo do grupo no momento da escolha de espécies de interesse, de forma que se estimulasse a discussão sobre as espécies nativas a partir do interesse dos(as) agricultores(as).

Além das fichas ilustradas, outras ferramentas participativas foram utilizadas visando reconhecer as espécies potenciais para uso nos $\mathrm{SAFs}$ da região. ${ }^{5}$

\footnotetext{
4 Nas reuniões de diagnóstico foi utilizada uma ferramenta participativa para identificação da fitofisionomia predominante do local onde o grupo está inserido, considerando que a região da Cantuquiriguaçu está em um ecótono entre a FES e a FOM e visando auxiliar na escolha das espécies mais indicadas para a fitofisionomia local.

5 Além da identificação da fitofisionomia predominante, foram utilizadas as ferramentas matriz de espécies arbóreas, em que os grupos citaram as espécies arbóreas conhecidas e as características delas que consideraram importantes, e quadro-síntese, que foi preenchido por cada família e no qual também constava quais eram as espécies de maior interesse.
} 
É importante salientar que o intuito do uso das fichas não foi desconsiderar o conhecimento local sobre as espécies florestais nativas nem esgotar as possibilidades de utilização de outras espécies de interesse dos(as), mas, sim, estimular a revalorização e o uso de espécies nativas por meio de um resgate histórico do conhecimento das famílias e/ou de possíveis novas informações sobre o uso múltiplo dessas espécies, aumentando o leque de possibilidades que os grupos têm para o planejamento.

\section{Resultados e discussões}

\subsection{As espécies florestais de ocorrência na região com importância para SAFs}

A partir do levantamento bibliográfico inicial (INCT, 2015; Isernhagen, 2001), foram levantadas 137 espécies, incluídas em 47 famílias, das quais foram constatados registros de ocorrência em $11 \mathrm{mu}$ nicípios do território da Cantuquiriguaçu: Candói, Laranjeiras do Sul, Pinhão, Três Barras do Paraná, Reserva do Iguaçu, Cantagalo, Quedas do Iguaçu, Rio Bonito do Iguaçu, Guaraniaçu, Ibema e Nova Laranjeiras. É importante destacar a dificuldade em encontrar levantamentos florísticos dos municípios da região, tendo-se recorrido a herbários virtuais (INCT, 2015). Sobre o número de espécies levantadas, destacam-se as famílias Fabaceae (27 espécies levantadas), Myrtaceae (12 espécies), Lauraceae (10 espécies), Rutaceae (7) e Euphorbiaceae (7). As famílias levantadas e o número de espécies por família estão na Tabela 2.

Dentre o total de espécies levantadas, foram consideradas prioritárias para uso em SAFs na região de estudo 72 espécies incluídas em 33 famílias botânicas (Tabela 3). Sobre essas espécies foram elaboradas as fichas ilustradas das espécies potenciais da região. Importa destacar que, dentre

TABELA 2 - Famílias e número de espécies por família listados na base de dados de espécies arbóreas da região da Cantuquiriguaçu (PR).

\begin{tabular}{cccccc}
\hline Família & $\mathbf{N}^{\mathbf{0}} \mathbf{S p}$. & Família & $\mathbf{N}^{\mathbf{0}} \mathbf{S p} \mathbf{r}$ & Família & $\mathbf{N}^{\mathbf{0}} \mathbf{S p}$. \\
\hline Adoxaceae & 1 & Celastraceae & 1 & Phytolaccaceae & 2 \\
Agavaceae & 1 & Combretaceae & 1 & Podocarpaceae & 1 \\
Anacardiaceae & 3 & Cunoniaceae & 1 & Polygonaceae & 1 \\
Annonaceae & 2 & Cyatheaceae & 1 & Proteaceae & 1 \\
Apocynaceae & 4 & Elaeocarpaceae & 1 & Rosaceae & 2 \\
Aquifoliaceae & 3 & Erythroxylaceae & 1 & Rutaceae & 7 \\
Araliaceae & 2 & Euphorbiaceae & 7 & Salicaceae & 4 \\
Araucariaceae & 1 & Fabaceae (faboideae) & 10 & Sapindaceae & 4 \\
Arecaceae & 1 & Lamiaceae & 3 & Sapotaceae & 2 \\
Asteraceae & 2 & Lauraceae & 10 & Simaroubaceae & 1 \\
Bignoniaceae & 2 & Malvaceae & 2 & Solanaceae & 1 \\
Boraginaceae & 3 & Meliaceae & 4 & Styracaceae & 1 \\
Cannabaceae & 1 & Fabaceae (mimosoideae) & 12 & Urticaceae & 2 \\
Canellaceae & 1 & Moraceae & 2 & Verbenaceae & 1 \\
Fabaceae (caesalpiniaceae) & 5 & Myristicaceae & 3 & Winteraceae & 1 \\
Caricaceae & 2 & Myrtaceae & 12 & Total de espécies & $\mathbf{1 3 7}$ \\
\hline
\end{tabular}

FONTE: Elaboração dos autores. 
as 37 espécies citadas por Castella \& Britez (2004)

fichas, o que significa $75 \%$ das espécies citadas

e Viani et al. (2011) como ocorrentes na região de

pelos autores.

transição entre FES e FOM, 28 estão incluídas nas

TABELA 3 - Lista de espécies arbóreas do território da Cantuquiriguaçu com potencial de utilização em SAFs. Legenda: Produtos florestais: aa - alimentação animal, al - alimentação humana, ap - apícola, ar - artesanato, co - comercial, cb - combustível (lenha, carvão), ma - madeira, me - medicinal, or - ornamental, pb - produto bioquímico, ec - ecológico; fitofisionomia: FES - Floresta Estacional Semidecidual, FOM - Floresta Ombrófila Mista, ecótono - transição entre FES e FOM; Fonte - detalhada na Tabela $1 .$.

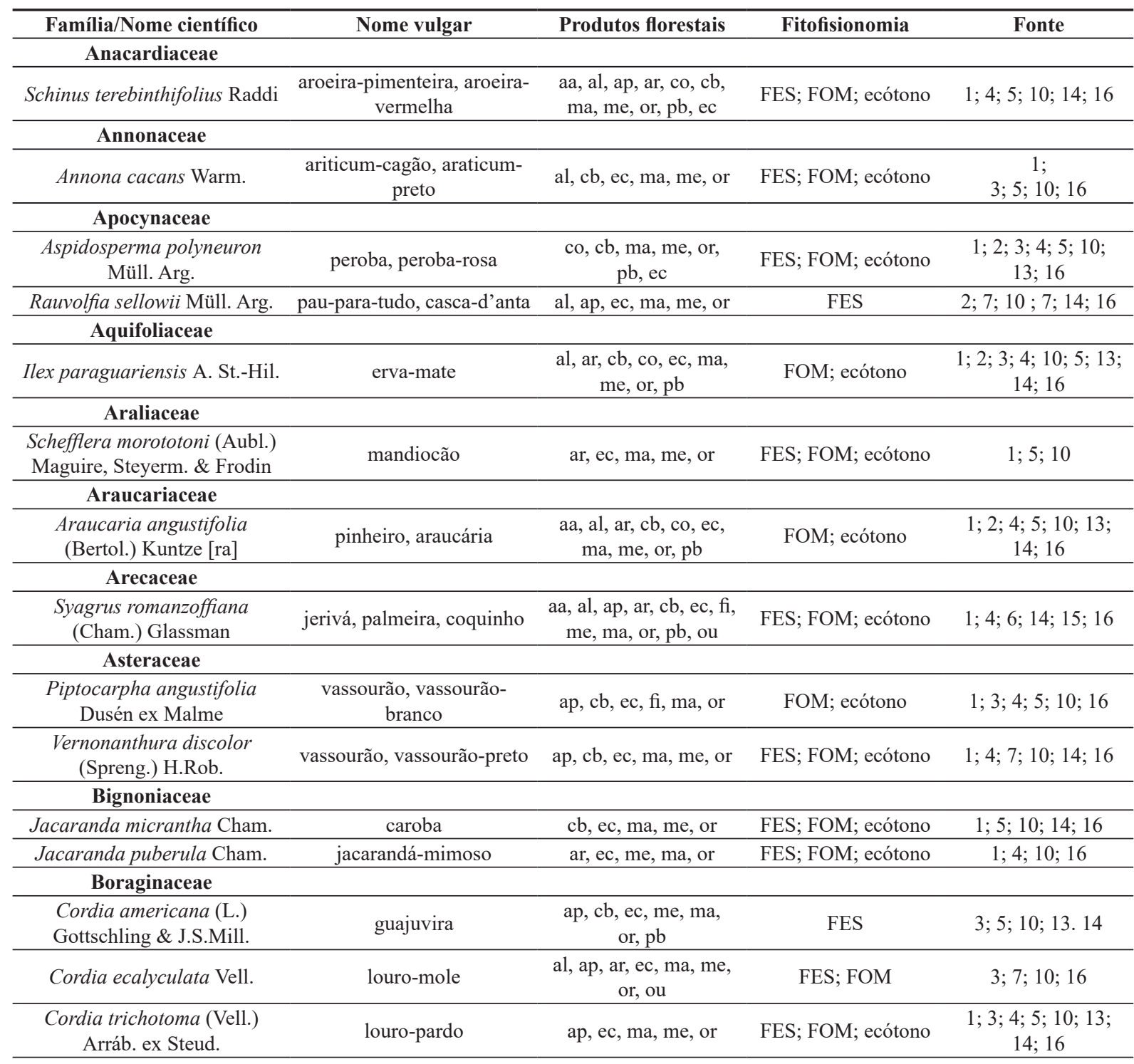

(continua) 
(Tabela 3 - Continuação)

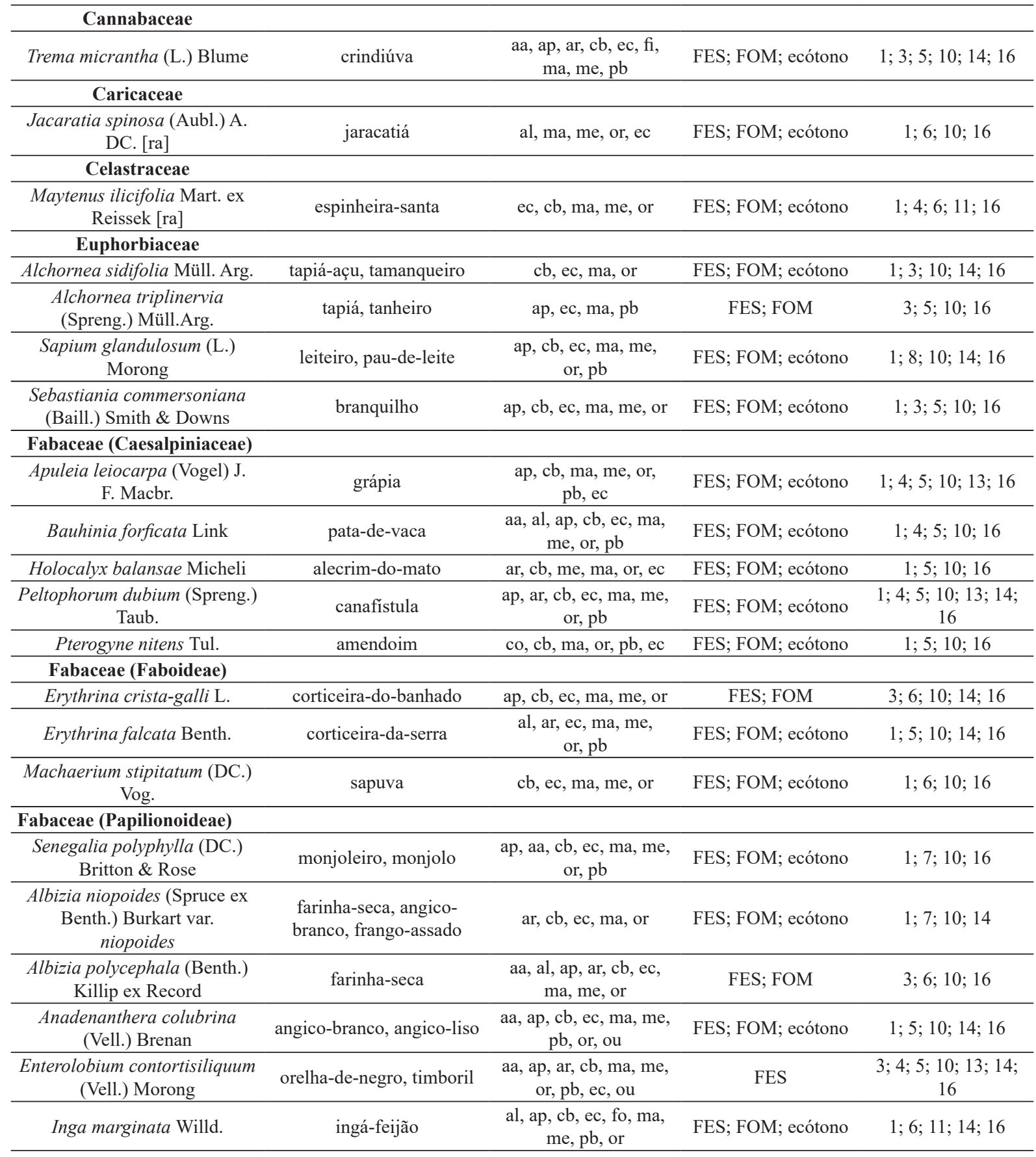


(Tabela 3 - Continuação)

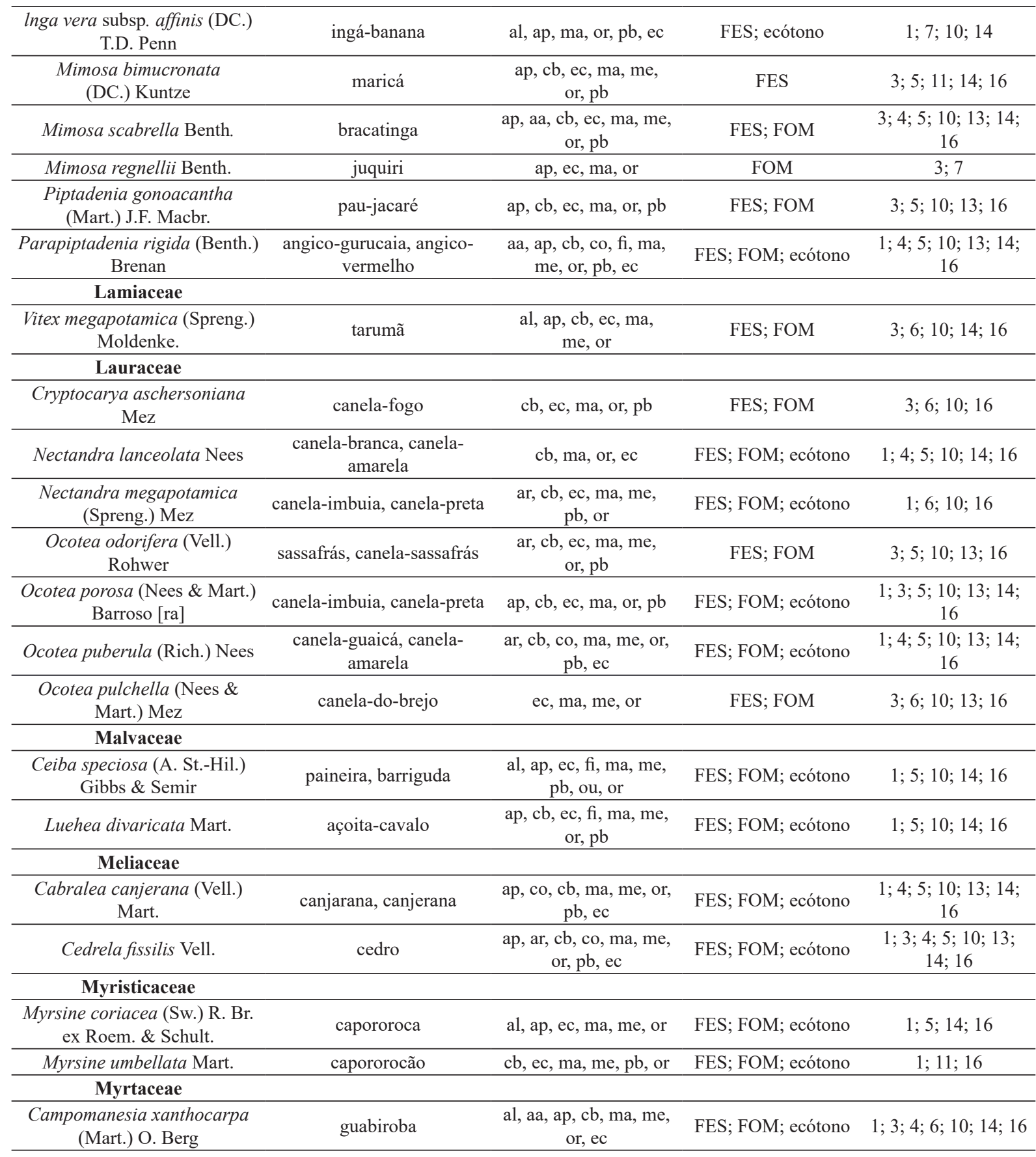


(Tabela 3 - Conclusão)

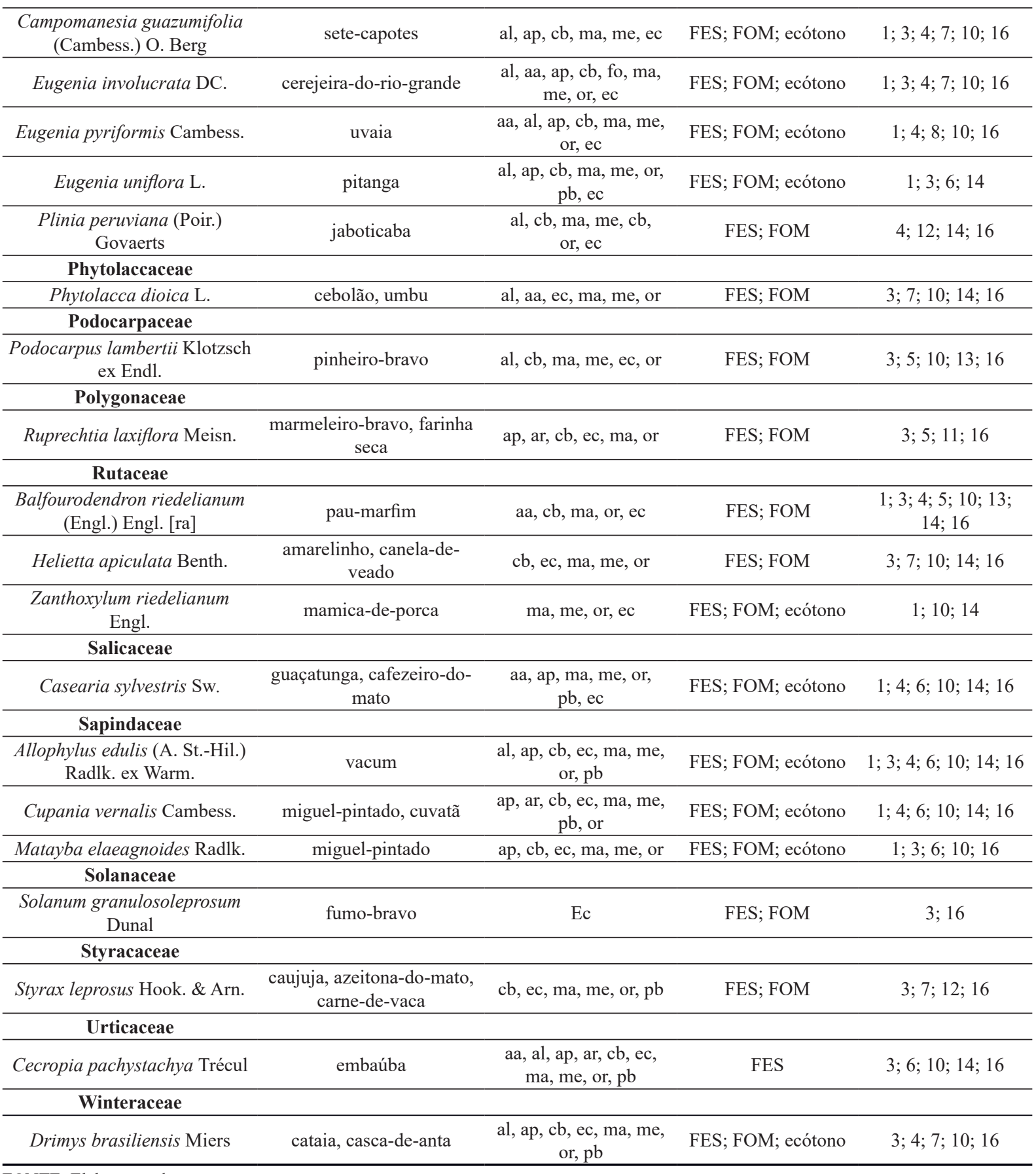

FONTE: Elaboração dos autores. 


\subsection{Uso das fichas ilustradas de espécies nativas no planejamento participativo de SAFS}

Em todos os grupos, o uso das fichas permitiu a troca de informações, entre os agricultores participantes, sobre as espécies regionais (Figura 3). Os grupos 2 e 3 foram os que conversaram por mais tempo e em todas as reuniões sobre as espécies das fichas, explorando-as com atenção. A ocorrência das espécies nas localidades dos grupos, dada segundo relatos dos agricultores, na maior parte das vezes condisse com o tipo florestal indicado na ferramenta participativa de identificação da fitofisionomia predominante. Grande parte das discussões foi sobre os usos potenciais, quando os grupos comentaram se os conheciam, questionaram se tinham dúvidas e conversaram sobre outros usos de que tinham conhecimento a partir de suas experiências.

Alguns depoimentos exemplificam essas discussões, a exemplo do grupo 3 , em que a agricultora 3A comentou sobre sua infância: "Esse aqui eu já vi também. Lá onde que nós morava tinha um pé bem a par do rio. Nós conhecíamos por tarumã. É uma frutinha bem escura, que a gente come e a boca fica preta, mas é gostosa de comer. Nós era tudo criança, nós bem comia essa fruta al". Ainda nesse grupo, o agricultor 3B comentou: "Crindiúva dá bastante aqui, pra abelha também, né? Mais tarde nós queremos ter umas caixa de abelha aqui". $\mathrm{Na}$ mesma sequência, as famílias conversaram sobre o uso do jaracatiá: "Esse não é o jaracatiá que dá pra fazer o doce? É? Será que pega aqui pra nós?" (agricultora 3B). Após o agricultor 3B confirmar a ocorrência da espécie na região, a agricultora lembrou: "Tem? Mas é, rala o galho e faz o doce. Não tem doce melhor que esse, e é gostoso". Dentre outras espécies, também comentaram sobre o angico:
"A lenha dele é forte. Se tiver um pau de angico, ele fica meio dia queimando e não apaga, tem uma brasa forte" (agricultora 3A). Esses depoimentos trazem o resgate de um conhecimento local, cultural e histórico sobre as espécies florestais e seus usos, mostrando que as fichas funcionam como uma memória histórica dos agricultores.

Apesar de ter atingido o objetivo inicial de incentivar o uso de espécies nativas, a utilização das fichas não foi realizada conforme sugerida. Nenhuma das famílias fez a separação por etapas até a seleção das espécies de interesse. As famílias utilizaram as fichas durante o desenho do croqui, quando era o momento de escolher as espécies que iriam compor o SAF. Nesse momento, exploraram o conteúdo das fichas observando e/ou discutindo se conheciam e se tinham interesse na espécie, principalmente segundo seu potencial de utilização, que em grande parte dos casos era de objetivo alimentício.

Assim, seu uso teve limitações por conta do volume de fichas e de informações, sendo uma sugestão para trabalhos futuros a articulação com ferramentas metodológicas que facilitem a compreensão e/ou a pré-seleção das fichas antes das reuniões. Possivelmente, mesmo que as informações incluídas nas fichas sejam importantes para o planejamento de SAF, havia muitos atributos para ser analisados ao mesmo tempo para todas as espécies, tornando o planejamento complexo. Sobre isso, percebeu-se que foram três os atributos mais notados pelos agricultores: usos potenciais, tipo florestal (fitofisionomia) e características ecológicas, sendo uma opção diminuir o número de informações das fichas de modo a manter apenas as mais importantes. Avaliou-se que pode ser interessante possibilitar mais tempo de contato das famílias com as fichas, seja realizando mais reuniões, dedicando mais tempo da reunião para conhecer e entender as 


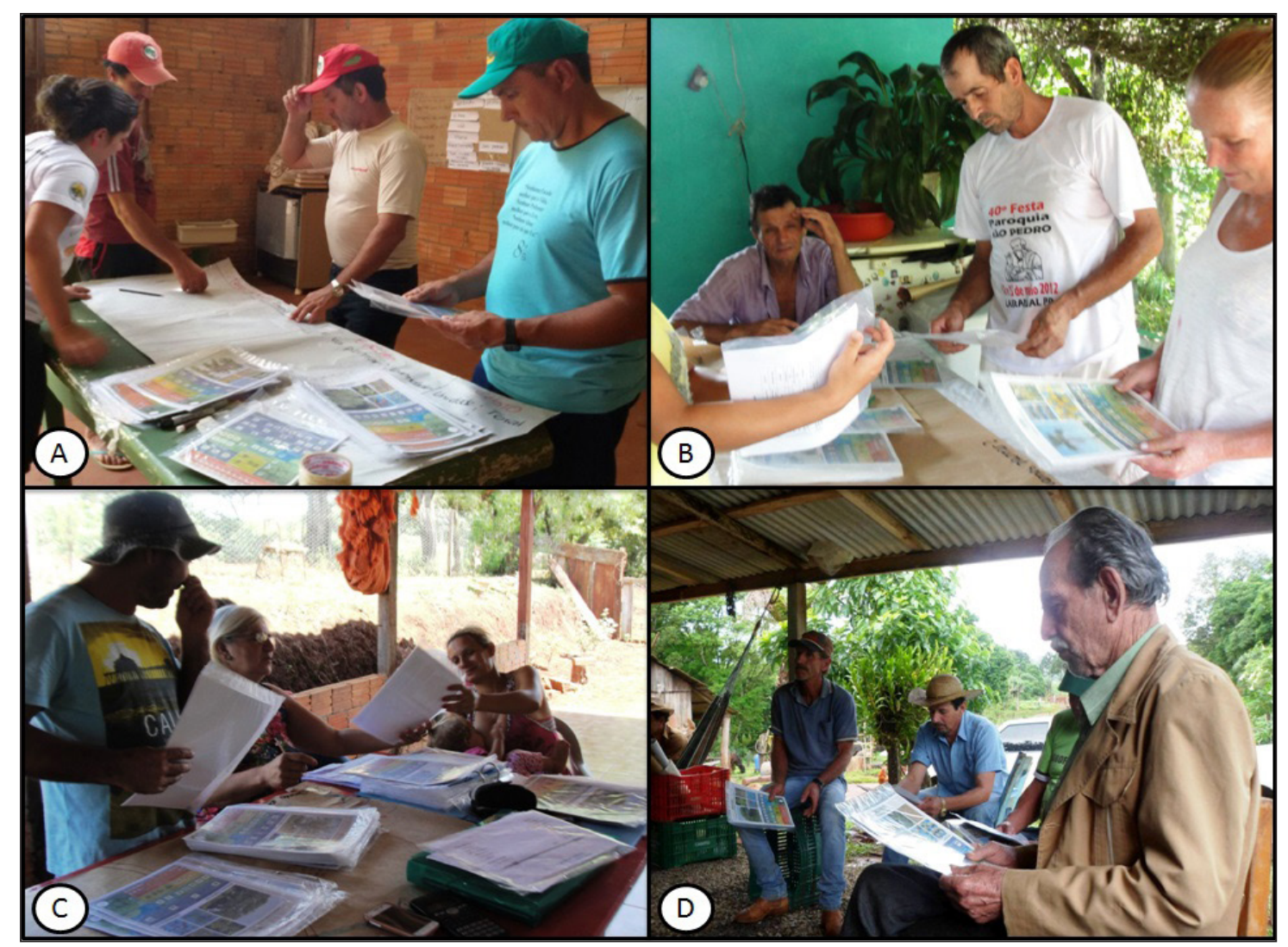

FIGURA 3 - Fotos da utilização das fichas ilustradas de espécies arbóreas regionais, nos quatro grupos participantes do presente trabalho, nas reuniões de planejamento de SAF. Legenda: A - Grupo 1; B - Grupo 2; C - Grupo 3; D - Grupo 4.

FONTE: Elaboração dos autores.

fichas, ou, ainda, deixando as fichas com as famílias no período entre uma e outra reunião, de forma que possam observá-las com mais tempo.

A pré-seleção das fichas antes das reuniões também poderia facilitar a visualização das informações, diminuindo o volume a ser explorado pelo grupo. Os resultados das reuniões de diagnóstico podem ser um indicativo de como fazer essa separação. Seguindo a ideia de etapas, um exemplo seria a pré-seleção de acordo com a fitofisionomia predominante, em que seriam separadas as espécies que ocorrem no tipo florestal da localidade onde o grupo está inserido. Outros níveis de pré-seleção podem ser feitos. Entretanto, é importante que sejam apresentadas todas as fichas, de forma que não se descaracterize o intuito de revalorização dos demais usos dessas espécies.

As famílias demonstraram níveis de interesse distintos em relação às fichas. Percebeu-se que quem mais se interessou por elas foram os agricultores que já valorizam as nativas como espécies potenciais para diversos usos, sendo poucos os que demonstraram ter essa visão. Por outro lado, grande parte das famílias demonstrou interesse, porém 
mais em relação às espécies frutíferas, sendo esse o uso considerado mais importante pelos grupos. Já as famílias que não tinham interesse em incluir espécies nativas ou outras além das que já tinham planejado não tiveram interesse pelo seu uso.

Outro aspecto a destacar é que, mesmo que as fichas tenham oferecido subsídios à escolha das espécies florestais a serem incluídas nos SAFs, prevaleceu o conhecimento dos agricultores, os quais escolheram, na grande maioria das vezes, as espécies de que tinham conhecimento e/ou com as quais tinham afinidade. Isso significa que o fato de ter sido levado conhecimento técnico sistematizado, nesse caso, não influenciou negativamente o processo participativo e o resgate do conhecimento local, mas funcionou como uma memória histórica dos agricultores em relação às espécies nativas florestais regionais e seus usos potenciais.

Há espécies que os agricultores conhecem, mas não sabem como utilizar, também por não saberem como fazer o aproveitamento correto. Esse foi o caso de algumas espécies com potencial medicinal, a exemplo da guaçatunga. Os agricultores do grupo 2 sabiam de seu potencial, mas disseram que " $o$ problema é que às vezes a gente sabe, mas não sabe a receita" (agricultor $2 \mathrm{C}$ ). Nesse grupo, surgiram com frequência discussões sobre possibilidades de beneficiamento das frutas, o que é exemplificado na fala do agricultor $2 \mathrm{C}$ : "É interessante conforme a fruta que der o suco, que der pra fazer algum aproveitamento. O problema nosso qual que é? Nós não temos conhecimento de como fazer e onde colocar, né [no sentido de vender]? Como fazer esse aproveitamento". O tarumã foi citado por produzir muitos frutos, mas as famílias não sabiam como aproveitá-los: "Nós não comemos, mas aqui carrega tanto, tanto que a gente fica olhando, mas tinha que fazer um aproveitamento desse negócio. Então, nós temos que descobrir. Lá em casa tem umas 'arvrinha' que já tá carregadinha de fruta. Eu já experimentei, mas ela tem tipo uma graxa" (agricultor 2C). Nesse sentido, as fichas podem dar um subsídio a mais na escolha das espécies: os potenciais de uso, além de indicados, poderiam estar detalhados na parte de trás, com informações como características do uso (receitas, beneficiamento, tratamento, etc.).

Algumas espécies não foram do interesse de algumas famílias, tanto por terem um comportamento mais agressivo no campo quanto por apresentarem alguma toxicidade ou alergia em algumas pessoas. Esse é o caso da aroeira. A agricultora 4C afirmou: "Eu sou inimiga da aroeira, dá coceira". Sobre a pata-de-vaca, houve a seguinte fala: "Se eu pudesse acabar com essas pata-de-vaca..." (agricultor 2D). Outro exemplo, citado pelo agricultor $2 \mathrm{C}$, é sobre o leiteiro, tido como um "inço que dá nos potreiro". Entretanto, para uma mesma espécie pode haver visões distintas entre as famílias e/ou grupos. Em outro grupo, a agricultora 3A também falou sobre o leiteiro: "Acho que é aquele que derruba as verrugas, que quebra as folhas e sai o leite, mas é bom esse pé".

Um outro exemplo de opiniões diferentes sobre uma mesma espécie é o da bracatinga. Sobre ela o agricultor 2D comentou que, "se der certo dela se propagar, pode chamar uma esteira pra tirar ela depois, porque é 'lazarenta', é que nem guanxuma se ela se dá bem". Ainda acrescentou que a lenha "só faz fumaça, segura muita umidade, e a madeira é assim muito encharcada". Em contrapartida, no mesmo grupo, o agricultor $2 \mathrm{C}$ comentou que seus cabritos ficavam gordos de tanto comer a folha da bracatinga. Falou também sobre o uso para fazer carvão. Já o agricultor $1 \mathrm{~B}$ comentou sobre duas bracatingas: "É bracatinga dessa grandona ou da baixinha? Tem a baixinha, que mais é só pra abelha, e que nem essa daqui é pra lenha". Isso indica que 
opiniões divergentes sobre o mesmo uso de uma espécie podem se dar pelo fato de que, em alguns casos, o mesmo nome popular pode se referir a mais de uma espécie.

No grupo 1 não houve muita discussão acerca das fichas. A família 1B já havia definido que o SAF teria foco nas espécies exóticas frutíferas, na araucária e na erva-mate e não teve interesse em incluir outras espécies nativas. No planejamento da família $1 \mathrm{C}$, comentaram muito pouco sobre as fichas. Fizeram a escolha das espécies nativas rapidamente, as explorando pouco. Nessa mesma reunião, um agricultor folheou todas as fichas, sem fazer comentários sobre elas. A família 1D finalizou seu planejamento, por motivos de logística, sem a presença do restante do grupo, não discutindo muito sobre as fichas. Entretanto, interessou-se muito por elas e as folheou por bastante tempo, escolhendo um grande número de espécies. Esse foi um dos SAFs planejados com maior diversidade.

No grupo 3, houve bastante discussão e troca de experiências, por parte das famílias, acerca de muitas espécies. Na segunda reunião de planejamento com o grupo, a agricultora 3B perguntou: "Foram vocês que fizeram essas fichas ai??". Quando a autora respondeu que sim, que elas foram feitas para este trabalho, a agricultora respondeu: "É bom, né?", o que indica boa aceitação do grupo. Ainda nesse grupo, o SAF da família 3B foi planejado com o objetivo de contemplar o turismo ecológico da unidade produtiva familiar, onde há duas cachoeiras. Nesse SAF foram incluídas apenas espécies nativas da região, com o intuito de servir como uma ferramenta para a educação ambiental: "É que pra essas aqui quero fazer tanto a visita pedagógica pros alunos que vão vir visitar quanto os orgânicos que tô produzindo. Aijá é uma atividade pra eles" (agricultor 3B). Durante a utilização das fichas, a família decidiu aumentar a área do SAF porque escolheu mais espécies do que o programado. Sobre isso, a agricultora 3B falou: "Vai faltar área para tudo isso que ele tá escolhendo. [...] Tudo isso aí você pegou?". Essa foi uma experiência prática do subsídio que as fichas podem dar à escolha das espécies nativas, aumentando o leque de possibilidades que a família tinha previsto para o planejamento. Um aspecto importante de citar é que esse grupo enfatizou bastante a fitofisionomia, entendendo bem os ícones sobre o "tipo de floresta" e dando preferência às espécies que ocorrem na FES, predominante na região onde está inserido.

No grupo 4, as fichas foram menos exploradas que nos grupos 2 e 3, mas ainda com bons resultados. No planejamento da família 4A, espécies ornamentais foram escolhidas para ser incluídas numa linha do SAF que beira a estrada, mostrando que outros potenciais de uso para além do alimentício foram valorizados. A agricultora $4 \mathrm{C}$, no planejamento do SAF de sua família, percebeu espécies de seu interesse ao explorar as fichas: "Guabiroba, ó. Guabiraba dá e capote também. É, vamo pôr essas aqui. [...] Uvaieira, paineira [...], sassafrás também. Será que dá pra conseguir muda? Sassafrás é pra madeira e medicinal [...]. Outra coisa que eu vou colocar também é a jaboticaba. Vamo colocar uma linha de jaboticaba, apesar que os passarinhos não deixam a gente colher ela, mas, quando ela tiver bem florescida, a gente vai comprar um sombrite pra pôr em volta". Esse exemplo demonstra que espécies que antes não foram notadas ou que não estavam sendo lembradas como espécies potenciais para compor SAFs foram resgatadas na memória dos agricultores a partir das fichas.

Considerando o que foi exposto pela maior parte das famílias no início da pesquisa, sobre possuírem certa resistência ao uso de espécies nativas, a disponibilização e o uso das fichas ilustradas no planejamento dos SAFs mostraram que 
essa é uma ferramenta eficiente na revalorização e no consequente uso dessas espécies. Assim, o emprego dessas fichas atingiu o objetivo de incentivar a utilização de espécies nativas, enfatizando e gerando discussões sobre sua ocorrência e seus potenciais de uso.

\subsection{Os SAFs planejados com o uso das fichas}

Dentre os quatro grupos participantes do presente trabalho, houve um total de 13 SAFs planejados. A diversidade de espécies variou bastante entre os planejamentos, resultando em SAFs com foco na produção: i) de uma ou duas espécies e pouco interesse na diversificação; ii) de uma ou duas espécies e com algum interesse na diversificação entre linhas; iii) de mais de duas espécies; e iv) de alta diversidade de espécies exóticas e nativas, mas sem foco específico em alguma(s) espécie(s).

Com relação às espécies nativas, é interessante notar que, dos 13 planejamentos, apenas um não incluiu espécies nativas para o plantio. No restante, foram incluídas as espécies nativas em menor ou maior quantidade, dependendo dos objetivos das famílias. Nota-se que grande parte das espécies arbóreas nativas foi escolhida a partir da influência do uso das fichas ilustradas, já que, dentre as 12 famílias que selecionaram espécies nativas, apenas duas já as tinham escolhido e não recorreram às fichas. Seis famílias selecionaram todas as nativas a partir das fichas, e as outras quatro famílias já tinham algumas definidas, mas consultaram as fichas para a seleção de outras espécies.
Dos 13 SAFs, dez tiveram a implantação iniciada antes do planejamento. Neles já estavam incluídas 47 espécies dentre as arbóreas exóticas e nativas e as de ciclo curto. Dessas, as que já estavam presentes em um maior número de SAFs foram banana (em $7 \mathrm{SAFs}$ ), laranja (6), poncã, mexerica e/ou tangerina (5), abacate (4), manga (4) e pêssego (4), sendo todas espécies frutíferas exóticas de valor comercial importante (Tabela 4). É importante notar que não há nenhuma espécie nativa dentre as espécies mais citadas. Entretanto, dentre as demais espécies incluídas, 12 das 17 espécies nativas já plantadas nos SAFs antes do planejamento estão presentes nas fichas, o que indica que estas contemplam boa parte das árvores nativas que já são utilizadas comumente pelos agricultores e agricultoras na região.

Durante a realização do planejamento com as famílias, o número de espécies selecionadas foi 77 dentre as arbóreas e as de ciclo curto, no total dos 13 SAFs. Dentre essas, as selecionadas mais vezes foram laranja (11 SAFs), banana (9), mexerica, tangerina e/ou poncã (9), jaboticaba (8), uvaia (8), abacate (7), pitanga (7), araucária (6), guabiroba (6) e pêssego (6) (Tabela 4). Nota-se que, ao contrário da listagem de espécies escolhidas antes do planejamento, cinco espécies nativas estão entre as mais escolhidas pelos(as) agricultores(as). Das 57 arbóreas nativas listadas durante o planejamento, 40 não possuem potencial frutífero ou alimentício, o que mostra uma valorização de espécies que possuem outros usos potenciais. 
TABELA 4 - Número de vezes em que as espécies foram utilizadas nos SAFs implantados antes do planejamento e que foram escolhidas durante o planejamento, sendo espécies arbóreas nativas $(\mathrm{N})$, incluídas ou não nas fichas ilustradas, arbóreas exóticas (E) ou espécies de ciclo curto (CC).

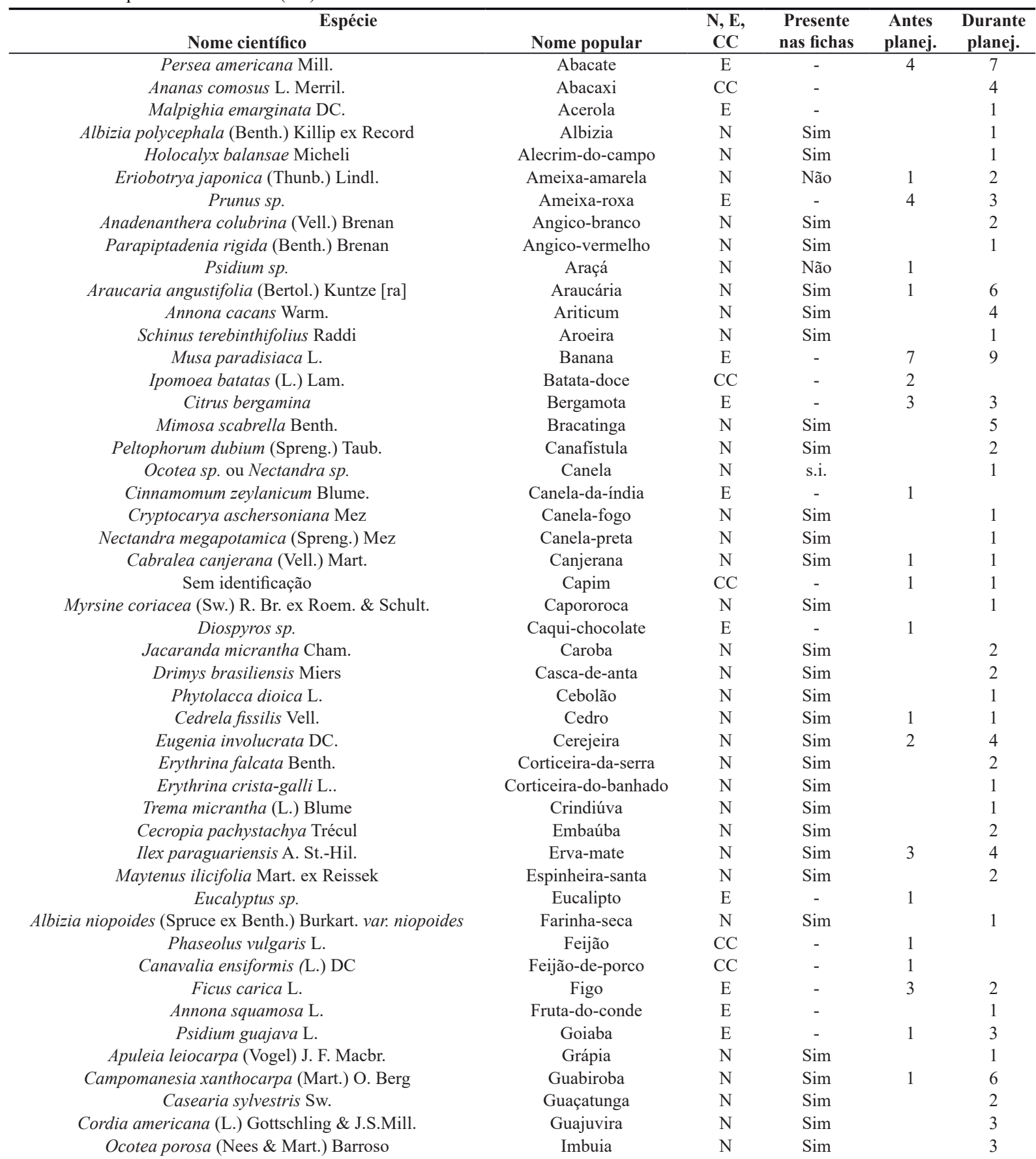




\begin{tabular}{|c|c|c|c|c|c|}
\hline $\begin{array}{l}\text { Espécie } \\
\text { Nome científico } \\
\end{array}$ & Nome popular & $\begin{array}{l}\mathbf{N}, \mathbf{E}, \\
\mathbf{C C}\end{array}$ & $\begin{array}{l}\text { Presente } \\
\text { nas fichas }\end{array}$ & $\begin{array}{l}\text { Antes } \\
\text { planej. }\end{array}$ & $\begin{array}{c}\text { Durante } \\
\text { planej. }\end{array}$ \\
\hline lnga vera subsp. affinis (DC.) T.D. Penn & Ingá-banana & $\mathrm{N}$ & Sim & & 3 \\
\hline Inga marginata Willd. & Ingá-feijão & $\mathrm{N}$ & Sim & & 1 \\
\hline Plinia peruviana (Poir.) Govaerts & Jaboticaba & $\mathrm{N}$ & Sim & 1 & 8 \\
\hline Artocarpus heterophyllus Lam. & Jaca & $\mathrm{E}$ & - & 2 & \\
\hline Jacaratia spinosa (Aubl.) A. DC. & Jaracatiá & $\mathrm{N}$ & Sim & 1 & 3 \\
\hline Actinidia deliciosa Liang \& Ferguson & Kiwi & $\mathrm{E}$ & - & 1 & \\
\hline Citrus sinensis L. Osbeck & Laranja & $\mathrm{E}$ & - & 6 & 11 \\
\hline Citrus aurantiun L. cf. & Laranja-crioula doce & $\mathrm{E}$ & - & & 1 \\
\hline Citrus aurantifolia (Christm.) S. & Limão taiti & $\mathrm{E}$ & - & 2 & 1 \\
\hline Litchi chinensis Sonn & Lixia & $\mathrm{E}$ & - & 1 & 1 \\
\hline Cordia ecalyculata Vell. & Louro-mole & $\mathrm{N}$ & Sim & & 1 \\
\hline Mangifera indica L. & Manga & $\mathrm{E}$ & - & 4 & 5 \\
\hline Passiflora edulis Sims & Maracujá & $\mathrm{CC}$ & - & 1 & \\
\hline Mimosa bimucronata (DC.) Kuntze & Maricá & $\mathrm{N}$ & Sim & & 1 \\
\hline Citrus reticulada Blanco & $\begin{array}{l}\text { Mexerica, tangerina, } \\
\text { poncã }\end{array}$ & $\mathrm{E}$ & - & 5 & 9 \\
\hline Zea mays L. & Milho & $\mathrm{CC}$ & - & 2 & \\
\hline Vaccinium myrtillus L. & Mirtilo & $\mathrm{N}$ & Não & 1 & \\
\hline Senegalia polyphylla (DC.) Britton \& Rose & Monjoleiro & $\mathrm{N}$ & Sim & & 2 \\
\hline C. reticulata $\mathrm{B} . \mathrm{X}$ C. sinensis $\mathrm{O}$. & Morgote & $\mathrm{E}$ & - & 1 & \\
\hline Carya illinoensis (Wang.) $\mathrm{K}$ & Noz-pecã & $\mathrm{E}$ & - & 1 & 1 \\
\hline Ceiba speciosa (A. St.-Hil.) Gibbs \& Semir & Paineira & $\mathrm{N}$ & Sim & & 2 \\
\hline Prunus sellowii Koehne & Pessegueiro-bravo & $\mathrm{N}$ & Não & 1 & \\
\hline Podocarpus lambertii Klotzsch ex Endl. & Pinheiro-bravo & $\mathrm{N}$ & Sim & & 1 \\
\hline Eugenia uniflora $\mathrm{L}$. & Pitanga & $\mathrm{N}$ & Sim & 3 & 7 \\
\hline Tibouchina granulosa (Desr.) Cogn. & Quaresma & $\mathrm{N}$ & Não & 1 & \\
\hline Ocotea odorifera (Vell.) Rohwer & Sassafrás & $\mathrm{N}$ & Sim & & 3 \\
\hline Campomanesia guazumifolia (Cambess.) O. Berg & Sete-capotes & $\mathrm{N}$ & Sim & & 5 \\
\hline Alchornea sidifolia Müll. Arg. & Tapiá & $\mathrm{N}$ & Sim & & 1 \\
\hline Vitex megapotamica (Spreng.) Moldenke. & Tarumã & $\mathrm{N}$ & Sim & & 2 \\
\hline Enterolobium contortisiliquum (Vell.) Morong & Timbaúva & $\mathrm{N}$ & Sim & & 3 \\
\hline Vitis vinifera $\mathrm{L}$. & Uva & $\mathrm{CC}$ & - & 2 & \\
\hline Eugenia pyriformis Cambess. & Uvaia & $\mathrm{N}$ & Sim & 1 & 8 \\
\hline Allophylus edulis (A. St.-Hil.) Radlk. ex Warm. & Vacum & $\mathrm{N}$ & Sim & & 2 \\
\hline Sem identificação & $\begin{array}{l}\text { Verduras (brócolis, } \\
\text { tomate, etc.) }\end{array}$ & $\mathrm{CC}$ & - & 2 & \\
\hline
\end{tabular}

FONTE: Elaboração dos autores. 
Considerando as escolhidas antes e durante o planejamento, houve um total de 96 espécies $^{6}$ listadas nos 13 SAFs. Dentre essas, 61 são arbóreas nativas, 25 são arbóreas exóticas e 10 são espécies de ciclo curto. Das nativas, 13 foram escolhidas tanto antes quanto durante o planejamento, 4 foram incluídas apenas nos SAFs já implantados anteriormente e 44 foram selecionadas somente durante o planejamento. Assim, se compararmos as listagens de espécies arbóreas que foram escolhidas antes e durante o planejamento, há uma inversão em relação à quantidade de nativas e exóticas. Esse resultado ocorreu não só em relação ao total de espécies escolhidas (ver Tabela 4), como em todos os grupos em separado, considerando o total de SAFs planejados no grupo (Tabela 5). Para todos os grupos, mais da metade das espécies arbóreas escolhidas durante o planejamento é nativa. No total, dentre as arbóreas, foram 17 nativas e 21 exóticas selecionadas antes do planejamento e 57 nativas e 18 exóticas escolhidas durante ele.

Considerando o total de 61 espécies nativas escolhidas antes e durante o planejamento, 53 constam nas fichas ilustradas. Em contrapartida, há 19 espécies que constam nas fichas, mas não foram escolhidas por nenhuma das 13 famílias. Sobre elas, há que se avaliar seu real potencial para uso nos SAFs da região: não foram escolhidas por ocorrerem pouco na região, por não serem conhecidas dos(as) agricultores(as) ou por não serem consideradas interessantes por eles? Também não se descarta a possibilidade de que outras famílias poderiam se interessar por elas de acordo com as circunstâncias e os objetivos com os SAFs.

Os resultados aqui apresentados demonstram que o uso das fichas ilustradas construídas no presente trabalho, articulado à utilização de metodologias participativas, resultou em um efeito positivo no estímulo à incorporação de espécies arbóreas nativas nos SAFs planejados, tendo funcionado como uma memória histórica para os(as) agricultores(as), que, com a ajuda das fichas, recordaram espécies que ocorrem em suas regiões e, assim, fizeram a escolha de quais são de seu interesse. Isso é refletido no fato de que 93\% das espécies arbóreas nativas escolhidas durante o planejamento estão incluídas no conjunto das fichas. Além disso, cinco espécies arbóreas dentre as oito mais citadas, durante o planejamento, para comporem os SAFs são nativas da região e compõem as fichas ilustradas construídas.

TABELA 5 - Número de espécies arbóreas nativas e exóticas escolhidas antes e durante o planejamento de SAF, por grupo participante.

\begin{tabular}{|c|c|c|c|c|c|c|c|c|c|c|}
\hline \multirow{2}{*}{$\begin{array}{c}\text { Antes/Durante o } \\
\text { planejamento }\end{array}$} & \multirow{2}{*}{$\begin{array}{l}\text { Nativa / } \\
\text { Exótica }\end{array}$} & \multicolumn{8}{|c|}{ Grupo } & \multirow[t]{2}{*}{ Total* } \\
\hline & & \multicolumn{2}{|c|}{1} & \multicolumn{2}{|c|}{2} & \multicolumn{2}{|c|}{3} & \multicolumn{2}{|c|}{4} & \\
\hline Antes do planejamento & Nativas & 1 & $38 \%$ & 2 & $15 \%$ & 0 & $0 \%$ & 2 & $50 \%$ & 17 \\
\hline \multirow{2}{*}{ Durante o planejamento } & Nativas & 25 & $66 \%$ & 11 & $58 \%$ & 45 & $84 \%$ & 26 & $74 \%$ & 57 \\
\hline & Exóticas & 13 & $34 \%$ & 8 & $42 \%$ & 8 & $16 \%$ & 15 & $36 \%$ & 18 \\
\hline
\end{tabular}

* Os totais não condizem com a soma das espécies citadas pelos grupos porque algumas foram citadas mais de uma vez. A soma dos totais não condiz com a soma de espécies citadas por todos os grupos na Tabela 4 porque houve espécies (13 nativas e 14 exóticas) citadas tanto antes quanto durante o planejamento.

${ }^{6}$ Esse número não é igual à soma das espécies selecionadas antes (47) e durante (77) o planejamento porque algumas espécies (28) foram escolhidas nos dois momentos. 


\section{Considerações finais}

O uso das fichas como ferramenta de apoio às metodologias participativas cumpriu com $o$ objetivo de incentivar o uso das espécies arbóreas regionais nos sistemas agroflorestais planejados. Tanto as discussões geradas acerca das espécies nativas durante as reuniões de planejamento quanto o resultado quantitativo de espécies nativas escolhidas para os SAFs planejados são reflexo do uso delas pelas famílias agricultoras. Além disso, os resultados obtidos na presente pesquisa mostram que as fichas ilustradas de espécies arbóreas nativas podem ser aliadas na utilização de metodologias participativas para o planejamento de SAF, sem que o caráter participativo seja desconsiderado, funcionando como uma memória histórica dos(as) agricultores(as) em relação às espécies nativas locais e seus usos potenciais.

Com relação às discussões realizadas, pode-se dizer que mais estudos poderiam ser feitos sobre o conhecimento dos(as) agricultores(as) com relação ao uso de espécies nativas. O resgate de espécies e de suas características a partir da literatura se mostrou, em muitas situações, complementar ao conhecimento local das famílias agricultoras, mas, em alguns momentos, divergente. Sendo assim, uma sistematização dos usos dessas espécies conhecidos pelos(as) agricultores(as) também seria de grande valia para dar subsídio à elaboração de novas fichas a serem utilizadas no planejamento de sistemas agroflorestais.

Apesar de ter atingido o objetivo inicial, a utilização das fichas não ocorreu exatamente conforme planejado inicialmente na pesquisa. Para isso, podem ser feitas algumas mudanças com relação às informações incluídas nelas, tornando-as mais apropriadas para o trabalho com agricultores e agricultoras. Da mesma forma, faz-se necessário diversificar as formas de inserção das fichas na metodologia de planejamento participativo dos SAFs, de forma a haver mais informações sobre os melhores momento e maneira de introduzi-las na discussão, facilitando seu uso e compreensão por parte das famílias agricultoras. Acredita-se que deve ser dado mais tempo para que as famílias compreendam e se apropriem das informações contidas nas fichas, seja pelo aumento do tempo para sua leitura e observação nas reuniões, seja deixando-as com as famílias no período entre duas reuniões.

Da mesma forma, a presente pesquisa estabeleceu as bases para a formulação dessas fichas, que podem ser ampliadas, em número de espécies e formações fitogeográficas, por outros trabalhos, tendo como base a estrutura didática e gráfica desenvolvida no presente trabalho. O conjunto das fichas produzidas pode ser acessado no link $<\mathrm{http} / / /$ neakarupora.net.br/PORTFOLIO_SAF_CANTU. $\operatorname{pdf}>$.

\section{Agradecimentos}

Às famílias agricultoras do Núcleo Luta Camponesa da Rede Ecovida de Agroecologia, que aceitaram participar deste trabalho, e à coordenação do núcleo pelo apoio na condução do trabalho. À Capes, pela concessão de bolsa à primeira autora. Ao NEA-Cantu/CNPq, pelo recurso destinado às coletas de campo. Ao Juan Manuel G. Canosa, pela colaboração no design gráfico das fichas ilustradas. 


\section{Referências}

ANA - Articulação Nacional de Agroecologia. Construção do conhecimento agroecológico: novos papéis, novas identidades. Rio de Janeiro - RJ: Secretaria Executiva da ANA. junho, 2007

Brasil. Lei $n^{\circ} 12.651$, de 15 de maio de 2012. Dispõe sobre a proteção da vegetação nativa; altera as Leis nos 6.938, de 31 de agosto de 1981, 9.393, de 19 de dezembro de 1996, e 11.428, de 22 de dezembro de 2006; revoga as Leis nos 4.771, de 15 de setembro de 1965, e 7.754, de 14 de abril de 1989, e a Medida Provisória no 2.166-67, de 24 de agosto de 2001; e dá outras providências. Brasília: DOU de 28/5/2012.

Campolin, A. I.; Feiden, A. Metodologias Participativas em Agroecologia. Corumbá-MS: Embrapa Pantanal, 2011. 21p. (Embrapa Pantanal. Documentos, 115). Disponível em: <http://www.cpap.embrapa.br/publicacoes/online/ DOC115.pdf $>$

Canosa, G. A. Base de dados de espécies arbustivo-arbóreas como ferramenta de avaliação de Projetos de Restauração de Áreas Degradadas. Seropédica/RJ, Monografia (Graduação em Ciências Biológicas) - Universidade Federal Rural do Rio de Janeiro, 2013.

Caporal, F. R. Agroecologia: uma nova ciência para apoiar a transição a agriculturas mais sustentáveis. Brasília: 2009. $30 \mathrm{p}$.

Carvalhaes, M. A.; Oliveira, R. E.; Santos, J. D.; Camilo, D. R.; Vedoveto, M.; Mazzella, P.R.; Korman, V. Produtos florestais madeireiros e não-madeireiros da Mata Atlântica brasileira: Oportunidades para a conservação e restauração florestal. Florestar Estatístico, 11(20), 9-17, 2008.

Carvalho, P. E. R. Espécies arbóreas brasileiras. Brasília, DF: Embrapa Informação Tecnológica; Colombo/PR: Embrapa Florestas, 2003. v. 1, 1039p.

Carvalho, P. E. R. Espécies arbóreas brasileiras. Brasília, DF: Embrapa informações Tecnológica; Colombo, PR: Embrapa Floretas, 2006. v. 2, 627p.

Carvalho, P. E. R. Espécies arbóreas brasileiras. Brasília: Embrapa Informação Tecnológica; Colombo/PR: Embrapa Florestas, 2008. v. 3, 593p.
Carvalho, P. E. R. Espécies arbóreas brasileiras. Brasília: Embrapa Informação Tecnológica; Colombo/PR: Embrapa Florestas, 2010. v. 4, 644p.

Carvalho, P. E. R. Espécies arbóreas brasileiras. Brasília: Embrapa Informação Tecnológica; Colombo/PR: Embrapa Florestas, 2014. v. 5, 634p.

Castella, P. R.; Britez, R. M. (Orgs.). A floresta com aracuária no Paraná: conservação e diagnóstico dos remanescentes florestais. Fundação de Pesquisas Florestais do Paraná/PROBIO. Brasília: Ministério do Meio Ambiente, 2004. 236p.

Cooperafloresta - Associação dos Agricultores Agroflorestais da Barra do Turvo e Adrianópolis. Quem Somos. Disponível em: <http://www.cooperafloresta.com/\#!loja-e-carrinho/c3m4>. Acesso em: fev. 2016

Corandin, L.; Siminski, A.; Reis. A. Espécies nativas da flora brasileira de valor econômico atual ou potencial: plantas para o futuro - Região sul. Brasília: MMA, 2001. 934p.

Coutinho, L. M. O conceito de Bioma. Acta Botânica Brasileira, 20(1), 2006.

Engel, V. L.; Parrota, J. A. Definindo a restauração ecológica: tendências e perspectivas mundiais. In: Kageyama, P. Y.; Oliveira, R. E. de; Moraes, L. F. D. de; Engel, V. L.; Gandara, F. B. (Org.). Restauração ecológica de ecossistemas naturais. Botucatu: FEPAF, 2003. p.1-26.

Fonini, R.; Lima, J. E. S. Agrofloresta e alimentação: o alimento como mediador da relação sociedade-ambiente. In: Steenbock, W.; Silva, L. da C. e; Silva, R. O. da; Rodrigues, A. S.; Perez-Cassarino, J.; Fonini, R. (Orgs.). Agrofloresta, ecologia e sociedade. Curitiba: Kairós, 2013.

Gliessman, S. R. Agroecologia: procesos ecológicos en agricultura sostenible. Turrialba, Costa Rica: CATIE, 2002. 359 p.

Gomes, G. C.; Schiavon, Ê. N.; Medeiros, C. A. B.; Verona, L. A.; Rodrigues, P. R. F. 50 árvores nativas e seus usos na visão do agricultor familiar de base ecológica Nilo Schiavon, Colônia São Manoel, Pelotas-RS. In: Anais do Congresso Brasileiro de Agroecologia, VIII. Porto Alegre, 2013. 
IAP - Instituto Ambiental do Paraná. Espécies Produzidas nos Viveiros do IAP. Disponível em: <http://www.iap.pr.gov. $\mathrm{br} / \mathrm{modules} /$ conteudo/conteudo.php? conteudo $=1353>$. Acesso em: jul. 2015.

IBGE - Instituto Brasileiro de Geografia e Estatística. Manual Técnico da Vegetação Brasileira. 2. ed. Rio de Janeiro: IBGE. 2012.

INCT - Institutos Nacionais de Ciência e Tecnologia. Herbário Virtual da Flora e dos Fungos, 2015. Disponível em: $<$ http://inct.florabrasil.net/>. Acesso em: jul. 2015.

Inoue, M. T.; Roderjan, C. V.; Kuneyoshi, Y. S. Projeto madeira do Paraná. Curitiba: FUPEF, 1984. 260p.

Isernhagen, I. A fitossociologia florestal no Paraná: listagem bibliográfica comentada. Curitiba/PR, Dissertação (Mestrado em Botânica) - Universidade Federal do Paraná, 2001.

ITCG - Instituto de Terras, Cartografia e Geociências. Mapa das Formações Fitogeográficas - Estado do Paraná. 2009

Klima L.; Hreçay, L.; Gorenstein, M. R.; Estevan, D. A.; Pompermayer, P. M. Levantamento da vegetação arbórea dos remanescentes naturais da Araupel S/A, Quedas do Iguaçu-PR. In: Anais do Simpósio Nacional de Inventário Florestal, II. Curitiba, 2013.

Longhi, S. J. Agrupamento e análise fitossociológica de comunidades florestais na sub-bacia hidrográfica do rio Passo Fundo - RS. Curitiba/PR, Tese (Doutorado em Ciências Florestais) - Universidade Federal do Paraná, 1997.

Lorenzi, H. Árvores brasileiras: manual de identificação e cultivo de plantas arbóreas do Brasil. v. 1, 4. ed. Nova Odessa/SP: Instituto Plantarum, 2002a. 384 p.

Lorenzi, H. Árvores brasileiras: manual de identificação e cultivo de plantas arbóreas do Brasil. v. 2, 2. ed. Nova Odessa/SP: Instituto Plantarum, 2002b. 384 p.

Lorenzi, H. Árvores brasileiras: manual de identificação e cultivo de plantas arbóreas do Brasil. v. 3. Nova Odessa/ SP: Instituto Plantarum, 2009. 384 p.

Pires, P. T. L. Alternativas políticas e jurídicas para a gestão de florestas de Araucária no estado do Paraná. Curitiba/ PR, Tese (Doutorado em Ciências Florestais) - Universidade Federal do Paraná, 2003.
Roderjan, C. V.; Galvão, F.; Kuniyoshi, Y. S.; Santos, É. P. dos. As unidades fitogeográficas do estado do Paraná, Brasil. Biogeographica, 4(77), 129-140, 2001.

Santilli, J. Agrobiodiversidade e direitos dos agricultores. São Paulo/SP: Editora Peirópolis, 2009. 519p.

Santos, A. J.; Hildebrand, E.; Pacheco, C. H. P.; Pires, P. T. L.; Rochadelli, R. Produtos não madeireiros: conceituação, classificação, valoração e mercados. Revista Floresta, 33(2), 215-224, 2003. doi: 10.5380/rf.v33i2.2275

Saueressig, D. Plantas do Brasil: Árvores Nativas. v.3, 1. ed. Irati/PR: Plantas do Brasil, 2015. 432p.

SER - Society for Ecological Restoration International. The SER primer on ecological restoration, 2004. Society for Ecological Restoration International, Science and Policy Working Group.Disponível em: <http://www.ser.org>. Acesso em: jun. 2011.

Sevilla-Guzmán E. La agroecologia como estratégia metodológica de transformación social. Reforma Agrária e Meio Ambiente, 2, 2006. Disponível em: <http://www.mstemdados.org/sites/default/files/Reforma $\% 20$ Agraria $\% 20 \mathrm{e} \% 20$ Meio\%20Ambiente\%20-\%20N\%2002_0.pdf>.

Silva, I. C. Sistemas Agroflorestais: conceitos e métodos. Itabuna: SBSAF, 2013. 308p.

SOS Mata Atlantica, Fundação; INPE - Instituto Nacional de Pesquisas Espaciais. Atlas dos remanescentes florestais do bioma Mata Atlântica: período de 2012-2013. Relatório Técnico, São Paulo, 2014.

Steenbock, W., Silva, R. O. Da, Vezzani, F. M., Seoane, C. E., Froufe, L. C. M., Características estruturais das agroflorestas desenvolvidas no âmbito da Cooperafloresta. In: Steenbock, W.; Silva, L. da C. e; Silva, R. O. da; Rodrigues, A. S.; Perez-Cassarino, J.; Fonini, R. (Orgs.). Agrofloresta, Ecologia e Sociedade. Curitiba: Kairós, 2013b, p.393-419.

Toledo, V. M.; Barrera-Bassols, N. A memória biocultural: a importância ecológica das sabedorias tradicionais. São Paulo: Expressão Popular, 2015. 272p.

Viani, R. A. G.; Costa, J. C.; Rozza, A. F.; Bufo, L. V. B.; Ferreira, M. A. P.; Oliveira, A. C. P. Caracterização florística e estrutural de remanescentes florestais de Quedas do Iguaçu, Sudoeste do Parana. Biota Neotrópica, 11(1), 2011. Disponível em: <http://www.biotaneotropica.org.br/v11n1/ en/abstract?article+bn01911012011.> 